\title{
The London Pond Survey
}

Thomas Langton

London has far fewer ponds than it had $\mathbf{1 0 0}$ years ago. In some parts $\mathbf{9 0}$ per cent of ponds have been lost since 1870, although the creation of gravel pits and lakes has compensated to a small extent. Such declines have made those ponds that are left of supreme importance for nature conservation, but many are neglected and harbour only remnants of their once rich flora and fauna. In 1984 Thomas Langton carried out a survey of London's ponds and other areas of standing water with the aim of identifying which ponds needed saving and managing for wildlife. This much needed work was made possible by the Greater London Council, which gave a grant to the FFPS for the purpose.

From the first signs of spring, and throughout the summer, a field survey was made of the 1600 or so waterbodies that exist today within the $400 \mathrm{sq}$ miles which make up the urban and green-belt areas of London. The distribution and ecological potential of the waterbodies and their surroundings were recorded, but of key importance was the search for the declining and protected great crested newt Triturus cristatus and its two congeners, the smooth newt $T$. vulgaris, and the palmate newt $T$. helveticus. These three amphibians are sensitive to habitat disturbance, in both their aquatic and terrestrial phases.

\section{The need to survey}

With the spread and development of cities, combined with increasing pressure on land at the urban-countryside boundaries, urban conservation is a focus of increasing interest in Europe London Pond Survey and throughout the world. Ponds, lakes, reservoirs, and other kinds of waterbodies have a special significance for conservation because, unlike streams, rivers and many of the other forms of wetland habitats, they are largely the result of human settlement over the last few hundred years, particularly in and around the London Basin. There is continuing pressure on aquatic habitats from agricultural and industrial operations such as drainage and water abstraction; water tables are lowered and ancient springs dried out. The semi-natural waterbodies that are left are increasingly important to maintain populations and distributions of species for a variety of conservation purposes.

During the 1970s, an increasing number of herpetologists in the UK began reporting a decline in number of populations of great crested newts. There were indications that the species was perhaps naturally rarer than the other two species, and in some way more vulnerable to habitat changes. Following protection under the Wildlife and Countryside Act (1981), and the Convention on the Conservation of European Wildlife and Natural Habitats (Bern Convention), a small number of County recorders began to confirm its localised status. One detailed survey by Keith Corbett of the British Herpetological Society of parts of north Kent and Surrey, and of south-east London gave even more reason for concern. This survey looked systematically at every waterbody in an area, and revealed declining and 'relic' population status for this species in a dilapidated and unmanaged series of aquatic habitats, which were often directly threatened by infill, waste disposal and other factors. 
National concern initiated a research exercise by the Nature Conservancy Council and Leicester Polytechnic to look in greater detail at the results of regional survey work, and at the types of waterbody particularly favourable for the species, and those not used at all. The London Pond Survey aimed to continue the south London survey north and to the west, and to complete as much 'blanket' area coverage as possible within the Greater London administrative region. In doing this, the data analysis would be as detailed as possible, within a defined administrative boundary, and suitable for applied conservation practice.

\section{Map research and fieldwork}

The project began in the first two months of the year with an assessment of the problems of site access, finding out where the waterbodies were located on the ground, and working out combinations of ponds that could be visited for daytime netting and night-time torch survey purposes. With a survey season of about 24 weeks, the average weekly visit rate was high, and efficient survey methods were necessary in order to enable as even and complete a coverage as possible.

The first edition Ordnance Survey maps, produced in the 1860 s at the scale of 25 inches to the mile, were of enormous value. These maps show individual trees, and features such as the tiny wells and kitchen garden ponds of Victorian London. As an extra bonus, each individual waterbody had been carefully painted blue and often annotated with a name or use for the pond at the time of survey. With cross-reference to modern maps and aerial photographs, the location of remaining waterbodies and the position of those lost were discernible. At the start of the year provisional site visits were carried out to investigate and arrange access with a large number of public and private land owners and managers.

When investigating the presence or absence of newts, two methods are generally used; traditional hand netting, and scanning the edge of waterbodies at night with a high-power torch. While the second method is faster, netting is sometimes the only sure way of sampling a heavily vegetated pond. Neither method can give an absolute certainty of absence. Many waterbodies in the London area are particularly neglected and shaded, often colonised by woody species such as willows Salix spp. Such conditions usually shade out submerged and emergent aquatic macrophytes, reducing richness and diversity of these types of plants, but give favourable conditions for torch surveys. Efficient systematic netting creates problems, uprooting plants, and disturbing the eggs and larvae of a great number of specialised invertebrates and other animals, so the torch method was mainly employed, with good results, until late July. After this, netting was used to assess the more open heavily vegetated waterbodies. While it was considered most important to establish the presence or absence of the three newt species, the numbers of animals seen or netted and their sex ratio were also recorded, as these reflect population size to some degree.

\section{The trend of decline}

By the end of the season, recording had allowed one or two visits to all but a small percentage of the total number of waterbodies. The late nineteenth-century maps revealed that the suspected trend of habitat loss was alarmingly real. Areas of London had lost over 90 per cent of the waterbodies present 120 years ago. While a small

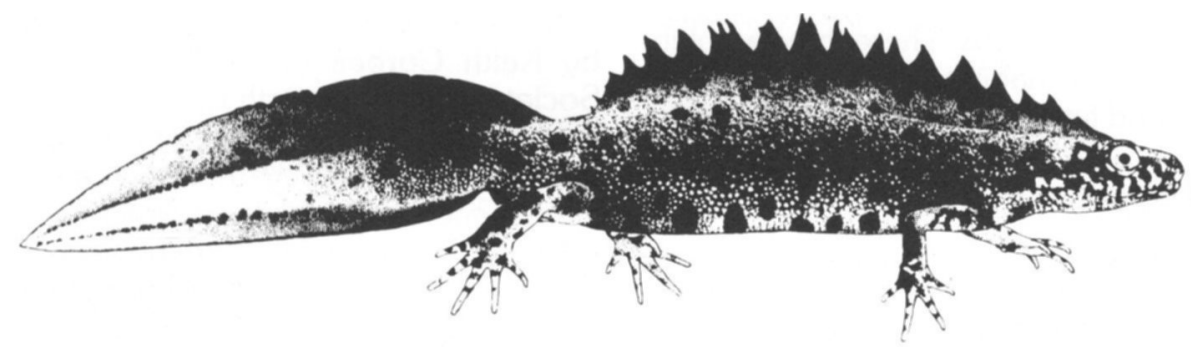

Great crested newt. 
number of gravel pits and new ponds and lakes have been created since 1870 , the crash in area of habitat parallels the statistics of other endangered habitats in Britain. The current rate of pond and lake loss was calculated at around 10-15 each year.

Soil type was found to be a significant factor in pond distribution; its water-holding capacity influenced the frequency of pond construction. On London Clay there were over 30 ponds per sq $\mathrm{km}$, while on permeable river terrace gravels there were far fewer. Of the 1600 or so remaining waterbodies in London, 61 locations for the great crested newt were identified, with only twice that number of palmate newt locations. Over 500 common newt populations were found, giving a ratio of $1: 2: 9$ for the relative abundance of these three species, respectively.

Of the 61 great crested newt locations, however, the number of animals recorded suggested that 41 (68 per cent) were very small, often with nonbreeding status. There were only 20 populations where 10 individuals or more were observed or netted. Two sites were of importance, in that counts by torchlight exceeded 100 individuals, meeting one of the criteria for statutory protection as a Site of Special Scientific Interest (SSSI). The area distribution of the populations was clearly clumped, and the relationship between present distribution and the historical distribution of aquatic habitats is to be described separately, in greater detail.

On a habitat basis, of the waterbodies remaining, less than 10 per cent were without need of management or restoration. About 60 per cent require substantial management to retain or restore their wildlife value, while several types of waterbody, for example those heavily stocked with ornamental wildfowl or predatory fish, surrounded by heavily managed ornamental gardens, have limited potential under their current management regimes. Of additional interest was the apparent reduction, in some areas, of the number of smaller garden fishponds, wells and water troughs indicated by the first edition maps. The 1984 field survey did not include London's garden ponds of less than $5 \mathrm{~m}$ diameter, and it is usually considered that recent popularity of small garden ponds offsets population losses for at least the common frog Rana temporaria, common toad Bufo bufo, and the smooth newt. A considerable amount of publicity for the survey and an appeal for information on newt locations only revealed seven garden populations of the great crested newt, all of which were introductions, and as yet offer no certainty of long-term population stability for the species. Consultation with most field workers working on studies or surveys of different plant and animal groups in the area reinforced the suggestion that palmate and great crested newts are not commonly found in the smaller garden ponds, though this is an area for further investigation.

\section{A strategy for progress}

The London Pond Survey concentrated on one particular problem facing the conservation of semi-natural habitats in an urban situation. In general, the results indicate the need for this strategic approach to such problems. Survey methods, protection and management techniques for amphibians and their habitats have been successfully carried out for several years in
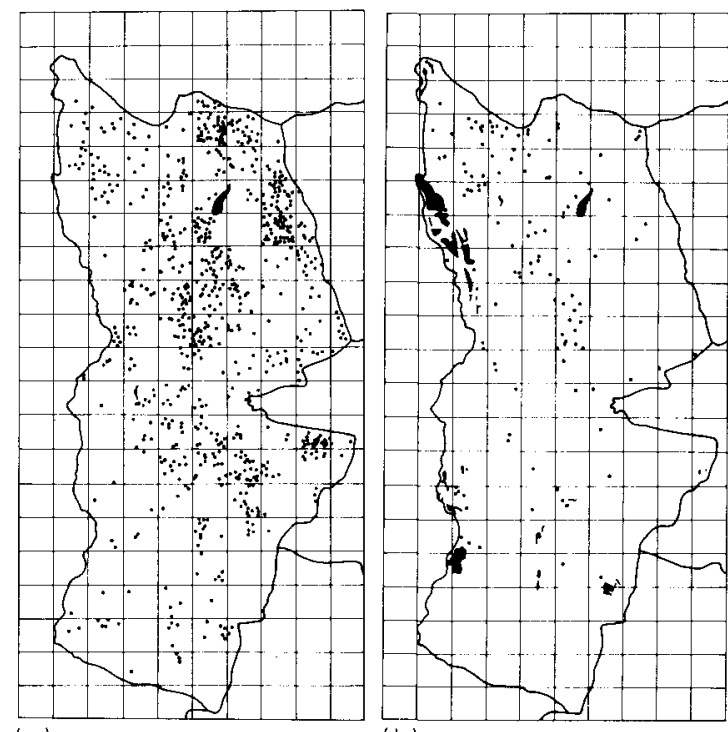

(a) (b)

Scale: eoch square $=1 \mathrm{~km}$

Figure 1. Distribution of waterbodies (excluding garden ponds) in the London Borough of Hillingdon in (a) 1870, (b) 1984. The loss of these waterbodies is 89 per cent, though the creation since then of a few gravel pits and other ponds and lakes has reduced the overall loss to 79 per cent. 


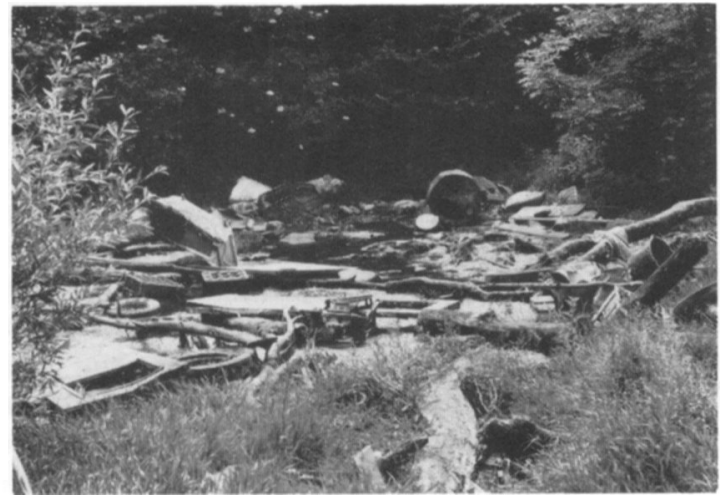

A London pond in need of restoration (Tom Langton).

other European countries. During 1984, a survey of habitats was carried out in London by the Greater London Council and the London Wildlife Trust in order to assist with the objective of acquiring an overall view of an area's ecological value, for decision-making with greater depth and understanding than previously possible. 'Pond' reports are being produced with this strategic brief in mind for each of the 33 Borough Councils, as it is at this level that local response from statutory or voluntary bodies to practical management problems can best be tackled. A programme of restoration for London's waterbodies has been worked out over the last two years, and consolidated using the survey information in order to pull together available resources in each area. Country Park management schemes, urban improvement and creation projects and government funding for environmental manpower programmes have played a major role in making this possible. With an increasing interest in the voluntary sector, a waterbody improvement strategy is not only feasible, but has grown from the pioneer work in south-east London and has already been implemented in the first winter following completion of the pond survey. The 1984/85 winter saw completion of the first three years' management programme for London's ponds. Sixty waterbodies had been restored, with a further 23 larger sites in progress. Of these, eight were relic great crested newt sites. At a further six secure sites, translocation of animals has been carried out to investigate the application of this technique at restored ponds. In addition, two pond-creation schemes, in urban areas in particular need of such sites, were of notable value.

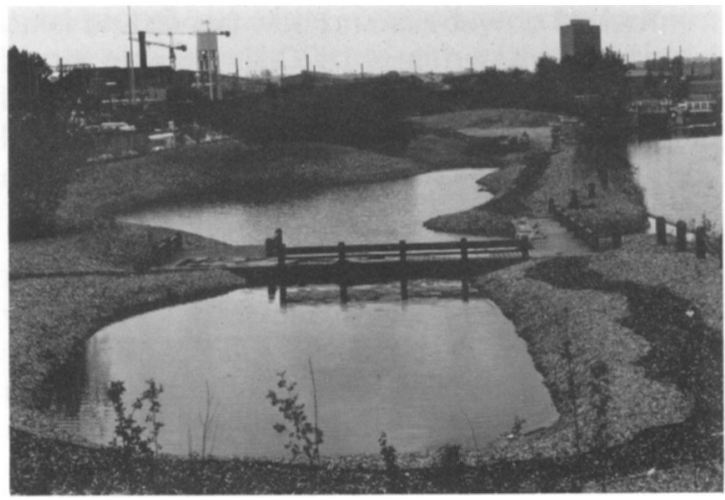

Pond creation in London (Tom Langton).

The restoration target for the next three autumnwinter management seasons is 400 , or 25 per cent, of the most important sites managed, and as many as possible of the rest identified and categorised in local development plans. It is hoped that this will assist with the integration of environmental conservation in local planning.

Combined with improved biological recording of species and communities, more subtle means for their protection and manipulation will be possible. Already, small voluntary groups funded through the World Wildlife Fund have restored and improved conditions for a significant proportion of remaining habitats inhabited by the great crested newt, one of Britain's most striking and beautiful endangered species.

\section{Acknowledgments}

The survey of London's Ponds was carried out by the FFPS following grant aid from the Greater London Council (GLC). Survey work was assisted by active members of the London Natural History Society, the London Wildlife Trust (LWT), and the British Herpetological Society Conservation Committee (BHSCC), in addition to many other individuals. Thanks are due to John A. and V. G. Burton, M. Catt, K. F. Corbett, C. Beckett, H. Inns, S. Rolland, C. Snell, V. Taylor and $B$. Whittaker.

Advice and help is acknowledged from Dr D. Dawson, Dr M. Game, Dr D. Goode and Dr J. Smart of the Greater London Council Ecology Section, and from the Staff of the British Map Library.

Pond restoration works have been carried out by the British Trust for Conservation Volunteers Ltd, following grant aid from the World Wildlife Fund. Particular thanks are due to Dr C. Tydeman. Tasks have been carried out by the BHSCC, LWT, and other local groups. Restoration work has been carried out by GLC (Parks and Gardens) and borough workparties, notably in the London Boroughs of Brent, Bromley, Camden, Ealing, Havering, Hillingdon and Sutton.

Oryx Vol 19 No 3 